\title{
TEXTILES AND HUMAN SKIN, MICROCLIMATE, CUTANEOUS REACTIONS: AN OVERVIEW
}

\section{Wen Zhong}

Department of Textile Sciences, Department of Medical Microbiology, University of Manitoba, Winnipeg, Canada

\section{Malcolm M. Q. Xing and Ning Pan}

Department of Biological System Engineering, University of California, Davis, California, USA

\section{Howard I. Maibach}

Department of Dermatology, University of California, San Francisco, California, USA

This article overviews research in the interdisciplinary area of textilelskin interaction and related cutaneous intolerance. Microclimate in the skinlclothing system and especially the skin responses relates to the moisture and heat transfer within this system and plays a critical role in skin irritation from textiles. A discussion is then given on skin irritation reactions to textiles, including intolerance caused by chemicals (dyes and finishes) and physical contactlfriction. Finally, two skin injuries, blisters and pressure ulcers, which are caused by physical contact, pressure, and friction, are documented. Despite the prevalent problems caused by ill textilelskin interactions, minimal efforts have been devoted to this field. In addition, the in vivo experimental studies infrequently lead to a solid conclusion. The cause may lie in the dramatic variation of skin conditions among individuals as well as among different anatomic sites of the same person. Another reason might be the lack of communications between researchers in the areas of textiles and dermatology.

Keywords: Textiles; Human skin; Microclimate; Cutaneous reaction; Irritation

\section{INTRODUCTION}

The skin is a large barrier organ that protects the human body from environmental hazards (heat, cold, chemicals, mechanical forces, etc.) and maintain the integrity of the body, whereas the clothing system provide an extra layer(s) of barrier to enhance the aesthetic, thermophysiological, and sensorial comfort of the wearer. However, direct contact and interactions between textiles and skin may cause reactions, even damage or diseases.

Address correspondence to Wen Zhong, Department of Textile Sciences, Department of Medical Microbiology, University of Manitoba, Winnipeg, MB R3T 2N2, Canada; Fax: 1-204-474-7593. E-mail: zhong@cc.umanitoba.ca 
This article overviews research in the interdisciplinary area of textile/skin interaction and related skin reactions and injuries. First, a brief description relates microclimate in the skin/clothing system and especially the skin responses to moisture and heat transfer within this system, because this plays a critical role in skin irritation and intolerance caused by textiles. Then follows a discussion on skin irritation reactions to textiles, including dermatitis caused by chemicals (dyes and finishes) and physical contact/friction. Finally, two skin injuries, blisters and pressure ulcers, which are caused by physical contact, pressure, and friction, are discussed. The role that textiles play in the prevention and formation of these injuries is examined.

\section{MICROCLIMATE}

The stratum corneum (SC) plays an important role in the clinical appearance of the skin as a result of its water-holding capacity and lipidic content $(1,2)$. From the deeper, highly hydrated layers of the epidermis and dermis, a passive flux of water takes place toward the more superficial SC layers, which have a relatively low water content. This is the so-called transepidermal water loss (TEWL) (3), which is a parameter to evaluate the function of SC as a barrier to prevent excessive water loss.

Extensive research work has been published on the topic of TEWL (4-7); however, knowledge about influence of textile materials to TEWL is limited.

In 1987, Hatch et al. reported an in vivo study of water content in the surface layers of human SC and water evaporation from its surface due to placement of fabric on skin for varying time periods (8). A lightweight fabric placed on skin produced no change in skin water content or evaporative water loss from the SC. Only for occluded treatments (e.g., fabric plus plastic film), did water content and evaporation increase as the covering materials remained for longer periods.

Another water loss route through skin is via perspiration or sweat, which is secreted by eccrine sweat glands deep in dermis. Water evaporation from the secretion absorbs heat and thus helps regulate body temperature in response to environmental changes. For humans to feel comfortable, a fairly narrow surface temperature and humidity must be maintained in the air immediately surrounding the body. Therefore, clothing plays an important role in regulating body temperature and controlling heat loss. The term microclimate, accordingly, has been used frequently to describe the environmental parameters that influence heat exchanges such as the temperature, humidity, and microspace airstream between the skin and clothing (9). Microclimate is an important factor for wear comfort and depends on properties, such as moisture and heat transport through the material, and on physiological and environmental conditions.

Clothing comfort has been extensively studied; however, less has been done in the skin response to fabric in various conditions. Hatch et al. wrote about in vivo cutaneous and perceived comfort response to fabric [10-15]; this series began with experiments in a simulated skin/fabric/microclimate system, which was composed of a modified Kawabata Thermolabo apparatus housed in a controlled environmental chamber (12). The three experimental fabrics (one cotton and two polyester fabrics with different fiber deniers) showed small differences in water vapor and air permeability as well as energy dissipation rates. The results suggested that these 
thermophysiological comfort parameters related more to fabric structures than to fiber contents. In addition, different mechanical and surface properties of fibers may contribute to variation in sensorial comfort of the experimental fabrics (10). They then documented water content and blood flow in human skin under garments worn by exercising subjects in a hot and humid environment (11); no significant differences was observed between the three experimental fabrics in terms of alteration in capillary blood flow, stratum corneum water content, skin evaporative water loss, or skin temperature (13). Surprised by the results, further investigations were performed when fabric patches were placed directly in contact with volar forearm skin of subjects instead of clothing worn loosely by subjects $(14,15)$. The experiments revealed that the SC hydration reduced after being in contact even with hydrophilic fiber (cotton).

Kwon et al. compared the physiological effects of the hydrophilic and hydrophobic properties of the fabrics in exercising and resting subjects with and without wind (16). Materials included three kinds of clothing ensemble with different moisture regains (wool-cotton blend with high moisture regain; $100 \%$ cotton with intermediate regain; $100 \%$ polyester with low regain). They concluded that the hydrophilic properties of the fabrics studied were of physiological significance for reducing heat strain, including skin temperature, clothing microclimate temperature and humidity, and pulse rate, during both exercise and rest especially when influenced by wind.

Generally, the experiments and analysis on the skin response to textile and clothing system have yet to led to commercial interventions. This may be caused by the individual differences among human subjects in terms of physical status and sensitivity. When it comes to the in vitro experiments, the difficulties lie in how to realistically represent the whole skin/fabric/microclimate system.

\section{SKIN REACTIONS TO TEXTILES}

The skin's irritant reactions to textiles may be caused by chemicals and/or physical contact and friction.

\section{Allergic Contact Dermatitis}

Numerous chemicals may be incorporated into the textiles and clothing during the processes from fiber formation, spinning, fabric construction to dyeing and finishing. These chemicals, when in contact with human skin, may cause allergic contact dermatitis (ACD).

Hatch and Maibach (17) reviewed the occurrence of dermatological problems caused by consumer exposure to dyes on clothing. Thirty-one dyes, mainly dispersed with anthraquinone or azo structures, may cause allergic contact dermatitis. Subsequently they reviewed the literature concerning textile dye dermatitis published during the decade before, and four new dye allergens were identified (18). Studies on ACD prevalence, the amount of ACD cases that are presented in a population, were summarized in 2000 (19). Most studies, however, were conducted in Europe, primarily Italy. And all the tests were performed by placing a dye, mostly dispersed dye, with unknown purity instead of a dyed fabric directly on the skin. 
Accordingly, they adopted the term "textile-dye ACD" in contrast to "colortextile ACD" (20), because the latter case involves more complicated factors, such as dye molecules transferred or released from textiles to the skin, perspiration fastness of the dyes. It was also reported that dyes to which a patient was patch test positive were infrequently identified in the fabric suspected to be the cause of the skin problems (21). This means that further investigation is desired in the diagnosis and management of colored-textile allergic contact dermatitis.

They further reviewed textile chemical finish dermatitis (22). Chemicals used on fabrics to improve 10 performance characteristics have been detected to have resulted in irritant or allergic contact dermatitis. The most significant problem is due to formaldehyde and $\mathrm{N}$-methylol compounds for durable press fabrics. An updated review on textile dermatitis caused by resins, additives, and fibers ended in 1994 (23). Textile formaldehyde resins for durable press finish was still the focus, because formaldehyde released from the resin was believed to be the causal agent.

Hatch provided a list of those textile chemicals (dyes, finishes, and additives) reported to cause textile dermatitis and the types of fabrics on which these chemicals are most likely to present (24). Clinical aspects of textile dermatitis and methods available to identify the specific chemical causing a skin problem are also covered.

However, the extent of the skin problems caused by textiles associated chemicals is hard to define and predict because of a series of factors including variation of skin's sensitivity, capacity of absorption and reaction among different people, transfer of irritant chemicals from textiles to skin, synergy of sweating, pressure and friction, etc.

\section{Skin Irritation by Physical Contact/Friction}

The frictional properties of skin are of interest to manufacturers of cosmetic products and to clinical dermatologists dealing with acute and chronic friction trauma such as blister and callus.

In 1990, a study on frictional properties of human forearm and vulvar skin was reported (25). The dynamic friction coefficient between skin and a Teflon probe was measured in vulvar and forearm skin of 44 healthy female volunteers, and its correlation with age, body weight, height, transepidermal water loss, and skin capacitance was obtained by using multiple-regression analysis. They observed that a higher friction coefficient of vulvar skin $(0.66 \pm 0.03)$ than that of forearm $(0.48 \pm 0.01)$ may be due to the increased hydration of vulvar skin. Age differences seem to exist for transepidermal water loss and friction coefficient in forearm but not in vulvar skin.

A similar study on skin friction properties involved human subjects of different gender and age (26). Measurements were obtained from 11 anatomical regions (i.e., the forehead, upper arm, volar and dorsal forearm, postauricular, palm, abdomen, upper and lower back, thigh, and ankle). The dynamic friction coefficient did not vary significantly between age and sex groups, but it varied considerably among the anatomical regions. They suggested that frictional properties of skin are dependent more on water content or nonapparent sweating, and the role of sebum secretion may be one possible factor. A later study suggested that the surface lipid content (SSL) plays a limited role in frictional properties of skin (27). 
Other studies on the influence of skin friction on the perception of fabric texture and pleasantness under a series of environmental conditions from neutral to hot-dry and hot-humid also revealed that moisture on the skin surface increased skin friction (28) and that fiber type and moisture influenced fabric-to-skin friction measurements (29). These reports agreed that moisture on the skin is more important than the fiber type or fabric construction parameters in determining the nature and intensity of fabric-to-skin friction and that glabrous skin friction changes less with wetting than with hairy skin.

Recent studies have further investigated the role of moisture, sebum, and emollient products on skin friction properties (30). Elkhyat et al. recorded the influence of hydrophilic/hydrophobic balance $(\mathrm{Hi} / \mathrm{Ho})$ of the skin surface on the friction coefficient by using both in vitro and in vivo experiments (31). They showed that the higher hydrophobia tendency of the surfaces, the lower friction coefficient. The friction coefficient, therefore, may quantify the influence of lubrificant/emolients/ moisturizers applied to the skin. The relationship between the friction coefficient and the hydrophilic/hydrophobic balance can be reversed in the presence of water and sebum on the forehead.

For the experimental methods to measure frictional coefficient of the skin, the earlier designs fall into two categories: using either a probe moved across the skin in a linear fashion (32) or a rotating probe in contact with the skin surface $(33,34)$, as also described in a review article (35). Recently, there are reports about instruments capable of measuring friction coefficient of skin in real time, such as a commercially available UMT series Micro-Tribometer. Either a stainless steel ball (36) or a copper cylindrical friction/electrical probe (37) was pressed onto the skin with a preset load and moved across the skin at a constantly low velocity. The UMT continuously monitored the friction force of the skin and the normal force applied by the probe to calculate the friction coefficient in realtime. Another commercial device for measuring surface properties of textile materials, a KES-SE Frictional Analyzer (38), was used in skin friction evaluation (39), where the friction coefficient (MIU) and its mean deviation (MMD) were used as the parameter to indicate surface friction. In addition, Tanaks et al. launched a study on a device for monitoring skin conditions, including roughness and softness (40). The device, so-called "Haptic Finger," was designed by using PVDF piezopolymer film as a sensory receptor. Signals obtained by sliding the sensor over skin surfaces were processed by wavelet analysis, and the dispersion of the power spectrum density in the frequency domain was obtained and found to be associated with roughness and hardness of skin in in vitro and in vivo experiments.

However, measurements of the friction coefficient of skin by different devices lack comparability, for there is still disagreement on which scientific law governs the relationship between the pressure and skin friction. The classic Amonton's law (41), which stipulates that the friction coefficient remains unchanged under varying normal loads and speeds of the probe (i.e., the opposing material used to measure the skin friction), was long challenged by numerous research works including some recent ones $(36,39)$, in which the friction coefficient is found to be inversely proportional to load (42).

Compared with what was achieved in measuring frictional coefficient of skin surface, far less work was performed in the assessment of frictional force between 
skin and fabric. This usually involved slowly pulling fabric samples across the surface of a subject's skin (i.e., forearm). The frictional force required to pull each fabric across the skin was recorded by a force transducer. The pressure between fabric and skin was often applied by suspending a weight to the free end of the fabric. The resulting irritation effects caused by friction could then be documented $(28,29)$. Other methods for measuring skin/fabric frictions were achieved by using strain gauge (43) or strained gauged flexure couples, which were arranged in a way to try to detect both normal and frictional force (44). Measurements can be made when wiping the material with the right index finger.

Literature concentrating on the skin irritation caused by contact and/or friction of clothing or other textile materials has been summarized by Hatch and Maibach (45). Six fibers, which had been reported to be linked to dermatological problems, were covered: nylon, for contact dermatitis and contact urticaria; wool, for acute and cumulative irritant dermatitis, aggravate atopic dermatitis, allergic contact dermatitis, and immulogical contact urticaria; silk, to atopic dermatitis and contact urticaria; glass fiber, to mechanical irritation; and spandex and rubber fibers. Some dermatitis, such as in the cases of nylon, spandex, and rubber fibers, were often caused by dye, finish, or fiber additive instead of fiber material itself.

A study on the effects of wearing diapers on skin showed that skin wetness was proportional to diaper wetness, and, with increased skin wetness, there were increased coefficients of friction and increased abrasion damage (46). Studying the electrostatic potentials generated on the surface of the scrotal area, the accumulated electrostatic charges on the pants were due to the friction of the pants with the skin, when different types of textile fabric were worn (47). The polyester pants showed the highest potential, whereas the polycotton pants produced less than half that level. The readings at daytime were higher than at night, probably due mainly because of the higher temperature and activities during the day. A related study even suggested that this electrostatic potential may be responsible for inhibiting hair growth (48).

In an effort to develop test methods to evaluate certain consumer products, such as feminine hygiene products and diapers, for their potential in causing mechanical irritation during use, Farage et al. investigated several test sites on the human body where normal daily activities provided the opportunity for movement and therefore friction (49). These studies indicate that a protocol using the back of the knee as a test site with an exposure regimen of 6 hours daily for 4 days proved to be the most effective test system for evaluating mechanical irritation.

Prolonged or extensive contact combined by pressure, friction, or shear between fabric and skin may lead to more serious problem or injuries, such as friction blisters and pressure ulcers, as discussed in the next section.

\section{SKIN INJURIES}

\section{Friction Blisters}

Friction blister is a frequently occurring skin problem associated with sports and vigorous activities. It can be critical if they occur during athletic competitions or military missions, when reduced performance or mobility becomes costly, 
injurious, or fatal. Accordingly, extensive research has been performed on the blister that causes fabric/skin friction and interactions.

Studies showed that blisters result from frictional forces that mechanically separate epidermal cells at the level of the stratum spinosum. Hydrostatic pressure causes the area of separation to fill with a fluid that is similar in composition to plasma but has a lower protein level (50).

There was a series of reports on a specially designed apparatus for producing friction blisters on human skin in the late 1960s and early 1970s (51-55). The instrument consisted of a rubbing head to which various materials (including textiles) could be firmly attached. The head could be moved over the surface of any chosen skin site at a selected stroking rate under a known amount of load. Frictional coefficient and temperature could also be recorded. Observations (54) and healing treatment (52) were performed on blisters formed by the instrument on human volunteers.

The other studies on friction blister (mostly foot blisters) formation and prevention were usually performed by recording the prevalence and size of blisters among a group of subjects with routinely heavy load of activities, such as athletes or military personals (56-59).

For example, Herring and Richie conducted a double-blind study to determine the effect of sock fiber composition on the frequency and size of blistering events in long-distance runners (57). Socks were tested, which were identical in every aspect of construction except fiber composition. One was composed of $100 \%$ acrylic, and the other $100 \%$ natural cotton fibers. Acrylic fiber socks were associated with fewer blistering events and smaller blister than cotton fiber socks.

Another examination into the effect of sock fiber contents on the incidence and severity of foot blister was reported by Knapik et al. (59): 357 military trainees were divided into three groups and assigned one of the three boot-sock systems: the standard military boot sock consisting of a wool-cotton-nylon-Spandex combination; the standard military boot sock with a thin inner or liner sock consisting of polyester; and a very thick, dense, prototype outer sock consisting of a wool-polypropylene combination over the same liner sock as the second group. The standard military sock with a polyester liner reduced the incidence of severe blisters, but the dense sock with the polyester liner reduced the overall incidence of blisters as well as the incidence of severe blisters.

Patterson et al. studied the blister attach rate among 100 cadets in a summer camp (58). Studies showed that women had higher risk than men. Cadets with a history of blisters in the 2 years before camp had an increased relative risk of blister formation. It was also suggested that the foot should be preconditioned to its footwear to prevent blister formation (e.g., wearing the boots over 20 hours per week during the 2 weeks immediately before camp).

Other measurements to prevent blister formation include lubrication (60), decreasing friction/shear (61), or reduce the skin surface hydration because moist skin increases frictional force (50). However, very dry or very wet skin would decrease frictional forces.

Reynolds et al. investigated the influence of an antiperspirant with emollient additives on frequency and severity of frictional blisters, hot spots, and irritant dermatitis by having 23 healthy subjects walking on a treadmill in a warm environment 
(62). However, the results showed that it reduces irritant dermatitis but does not reduce foot-sweat accumulation, blister or hot spot incidence, or blister severity. A later study was carried out on the effect of an antiperspirant in reducing foot blisters during hiking (63); it might be effective in reducing foot blisters during hiking; however, a side effect of skin irritation was observed.

Despite extensive studies on friction blisters, the prevalence or severity of friction blister is still difficult to predict, let alone a simple solution to prevent its formation. The cause may lie in the dramatic variation of skin conditions (surface roughness, hydration, adhesion between skin layers, etc.) among individuals as well as among different anatomic sites of the same person.

\section{Pressure Ulcers}

Pressure ulcer, defined as an area of localized damage to the skin and underlying tissue caused by pressure, shear, friction, or a combination of these (64), presents a significant health care threat to hospitalized patients. Approximately 1 million hospitalized and nursing home patients are diagnosed with pressure ulcers and about 60,000 die as a result of pressure ulcer complications annually (65). Related costs have been estimated to exceed $\$ 1$ billion annually in the United States $(66,67)$.

According to etiology of pressure ulcer formation, when compressive and/or shear/friction forces reach a certain threshold (combination of intensity and duration), there is occlusion and thrombosis of capillary at pressure points or areas. This results in tissue anoxia with release of toxic metabolites and, ultimately, cell death and tissue necrosis. Thus, pressure ulcers are formed $(64,68)$.

As the principal mechanical factors that result in ulcer formation, the combination of pressure and shear/friction has been reported to be devastating to the skin and underlying tissues. Dinsdale demonstrated that when both pressure and friction were applied to the skin of swine, a pressure as low as $45 \mathrm{mmHg}$ was sufficient to cause an ulcer, whereas $290 \mathrm{mmHg}$ of pressure was required if no friction was present (69). Davis presented hypotheses of three scenarios with different shear and vertical force conditions that could lead to skin ulceration (70): at a localized area the skin may tend to slip 1) towards, 2) away from, or 3) parallel to a neighboring skin region where the two skin regions possess different friction coefficients against the slippage.

Despite all the different scales for assessing pressure ulcers, there are some common factors that are included or considered $(71,72)$ : pressure, shear/friction, and liquid/moisture. Among the overwhelming publications in pressure ulcers research including updated reviews $(59,73-75)$, little has been devoted to the role that textiles play in the formation and prevention of pressure ulcer, although textiles could interfere with all the following important factors associated with pressure ulcers:

1. Pressure. Although the fabrics (clothing and beddings) alone cannot do much to reduce the pressure experienced by patients [other solutions like repositioning, using pillows/cushions/foam wedges, or using low-pressure mattress or seat that can better perform the job (76-78)], it would play a critical role in governing the 
shear and friction actions on human skin once pressure and body motion are involved.

Nevertheless, there have been studies on special designed clothing/socks in terms of their effectiveness in prevention and management of pressure ulcers. For example, padded hosiery has been reported to reduce plantar pressures in patients at risk of ulceration (79). Specially designed socks, when worn with suitable shoes, may be an acceptable and inexpensive addition to existing methods of protecting the high-risk insensitive diabetic foot ulceration (80).

2. Shear stress and friction. The surface smoothness of fabrics and stiffness/flexibility of fiber and fabric may be two of the important factors in determining the shear and friction experienced by patients. Little has been done on the effort of shear/friction monitoring in preventing pressure ulcers. Snycerski and Frontczak presented a design and manufacture of a double-layer woven fabric for bed sheet with different friction coefficients on both sides of the fabric (81): the bottom side of the bed sheet has a higher friction coefficient to limit the slip between bed sheet and underlying bedding materials and, therefore, reduce bed sheet wrinkling; the up side of the bed sheet has a low friction coefficient to allow easier and smoother position change for patients. However, the efficacy of this sheet in controlling pressure ulcers has not been reported.

3. Liquid/moisture or skin hydration. Appropriate moisture conditions should be kept to prevent or reduce ulceration. An overly dry condition may lead to a skin more vulnerable to cracking. Conversely, a wet condition (because of incontinence and/or perspiration) may cause skin maceration and lower the tissue tolerance to shear stress and friction (68). It may also create a favorable condition for the growth of microorganisms. The clothing (and the bedding) system plays an important role in moderating liquid and moisture to maintain a healthier micro-climate near the skin surface.

The role that textiles play in the formation and prevention of pressure ulcers is generally understudied, despite the fact that textiles (clothing and bedding) could have considerable influence on the factors (pressure, shear/friction, and skin hydration) contributing to skin ulceration. More research effort, therefore, is expected in this field for a better understanding as well as a more efficient way in controlling the problem.

\section{SUMMARY}

Skin provides the critical first defense mechanism for the body in dealing with external hazards. Clothing fabrics and the skin surface constitute a buffering system that establishes a thermal and sensorial state of comfort to maintain human health and normal functions. A failure of fabric/skin regulatory interactions can lead to various problems, from thermophysiological discomfort, irritation, to injuries such as blisters and pressure ulcers.

We reviewed here the existing studies in the fabric/skin interactions, related irritation reactions and injuries. The microclimate between clothing and skin surface, where fabric/skin interactions take place, has been discussed. Skin irritations, caused by both textile chemicals and physical skin-textile contact/friction, have also been 
reviewed. The final section deals with skin injuries, blisters, and pressure ulcers, caused by physical contact, pressure, and friction.

Despite the prevalent problems caused by ill textile/skin interactions, few research efforts have been devoted to this field. In addition, the existing in vivo experimental studies have rarely led to any significant results and solid conclusions. The cause may lie in the dramatic variation of skin conditions (surface roughness, hydration, adhesion between skin layers, etc.) among individuals as well as among different anatomic sites of the same person. Another reason might be the lack of communications between researchers in the areas of textiles and dermatology.

A literacy summary table is provided at the end of the reference list (Appendix 1).

\section{ACKNOWLEDGEMENT}

Authors would appreciate the support from National Textile Center with grant NTC S05-CD04.

\section{REFERENCES}

1. Rogiers V, Houben E. Transepidermal water loss measurements in dermato-cosmetic sciences. In: Fluhr JEA, ed. Bioengineering of the the Skin: Water and the Stratum Corneum. Boca Raton, FL: CRC Press; 2005:63-76.

2. Tagami H, Hashimoto-Kumasaka K, Terui T. The stratum corneum as a protective biological membrane of the skin. In: Tagami H, Parish JH, Ozawa Y, eds. Skin: Interface of a Living System. Perspective for Skin Care System in the Future. Amsterdam: Elsevier; 1998:23-37.

3. Wilson DR, Maibach HI. Transepidermal water loss: a review. In: Leveque JL, ed. Cutaneous Investigation in Health and Disease: Noninvasive Methods and Instrumentation. New York: Marcel Dekker; 1989:113-133.

4. Levin J, Maibach $\mathrm{H}$. The correlation between transepidermal water loss and percutaneous absorption: an overview. J Control Release 2005; 103(2):291-299.

5. Fluhr J. Bioengineering of the the Skin: Water and the Stratum Corneum. 2nd ed. Dermatology. Boca Raton, FL: CRC Press; 2005:420.

6. Warren $\mathrm{R}$, et al. Transepidermal water loss dynamics of human vulvar and thigh skin. Skin Pharmacol Physiol 2005; 18(3):139-143.

7. Weigmann HJ, et al. Comparison of transepidermal water loss and spectroscopic absorbance to quantify changes of the stratum corneum after tape stripping. Skin Pharmacol Physiol 2005; 18(4):180-185.

8. Hatch KL, Wilson DR, Maibach HI. Fabric-caused changes in human-skin-invivo stratum-corneum water-content and water evaporation. Textile research journal 1987; 57(10):583-591.

9. Cena K, Clark JA, Wrocawska P. Bioengineering, thermal physiology, and comfort. Amsterdam: Elsevier Scientific Pub. Co.; 1981.

10. Barker RL, et al. Invivo cutaneous and perceived comfort response to fabric. 2. Mechanical and surface related comfort property determinations for 3 Experimental knit fabrics. Textile Research Journal 1990; 60(8):492-494.

11. Hatch KL, et al. Invivo cutaneous and perceived comfort response to fabric. 3. Watercontent and blood-flow in human skin under garments worn by exercising subjects in a hot, humid environment. Textile Research Journal 1990; 60(9): 510-519. 
12. Hatch KL, et al. Invivo cutaneous and perceived comfort response to fabric. 1. Thermophysiological comfort determinations for 3 experimental knit fabrics. Textile Research Journal 1990; 60(7):405-412.

13. Markee NL, et al. Invivo cutaneous and perceived comfort response to fabric. 4. Perceived sensations to 3 experimental garments worn by subjects exercising in a hot, humid environment. Textile Research Journal 1990; 60(10): 561-568.

14. Hatch KL, et al. Invivo cutaneous response to fabric. 5. Effect of fiber type and fabric moisture-content on stratum-corneum hydration. Textile Research Journal 1992; 62(11): 638-647.

15. Hatch KL, et al. In vivo cutaneous and perceived comfort response to fabric. 6 . The effect of moist fabrics on stratum corneum hydration. Textile Research Journal 1997; 67(12): 926-931.

16. Kwon A, et al. Physiological significance of hydrophilic and hydrophobic textile materials during intermittent exercise in humans under the influence of warm ambient temperature with and without wind. Eur J Appl Physiol Occup Physiol 1998; 78(6):487-493.

17. Hatch KL, Maibach HI. Textile dye dermatitis. A review. J Am Acad Dermatol 1985; 12(6): 1079-1092.

18. Hatch KL, Maibach HI. Textile dye dermatitis. J Am Acad Dermatol 1995; 32(4):631-639.

19. Hatch KL, Maibach HI. Textile dye allergic contact dermatitis prevalence. Contact Dermatitis 2000; 42(4):187-195.

20. Hatch KL, Motschi H, Maibach HI. Textile-dye and colored-textile allergic contact dermatitis. Exogenous Dermatology 2003; 2:206-209.

21. Hatch KL, Motschi H, Maibach HI. Disperse dyes in fabrics of patients patch-testpositive to disperse dyes. Am J Contact Dermat 2003; 14(4):205-212.

22. Hatch KL, Maibach HI. Textile chemical finish dermatitis. Contact Dermatitis 1986; 14(1):1-13.

23. Hatch KL, Maibach HI. Textile dermatitis - an update. 1. Resins, additives and fibers. Contact Dermatitis 1995; 32(6):319-326.

24. Hatch KL, Maibach HI. Textiles. In: Kanerva L, et al. eds. Handbook of Occupational Dermatology. Berlin: Springer Verlag; 2000:622-636.

25. Elsner P, Wilhelm D, Maibach HI. Frictional properties of human forearm and vulvar skin: influence of age and correlation with transepidermal water loss and capacitance. Dermatologica 1990; 181(2):88-91.

26. Cua AB, Wilhelm KP, Maibach HI. Frictional properties of human skin: relation to age, sex and anatomical region, stratum corneum hydration and transepidermal water loss. $\mathrm{Br}$ J Dermatol 1990; 123(4):473-479.

27. Cua AB, Wilhelm KP, Maibach HI. Skin surface lipid and skin friction: relation to age, sex and anatomical region. Skin Pharmacol 1995; 8(5):246-251.

28. Gwosdow AR, et al. Skin friction and fabric sensations in neutral and warm environments. Textile Research Journal 1986; 56(9):574-580.

29. Kenins P. Influence of fiber-type and moisture on measured fabric-to-skin friction. Textile Research Journal 1994; 64(12):722-728.

30. Sheu HM, et al. Human skin surface lipid film: An ultrastructural study and interaction with corneocytes and intercellular lipid lamellae of the stratum corneum. British Journal of Dermatology 1999; 140(3):385-391.

31. Elkhyat A, et al. Influence of the hydrophobic and hydrophilic characteristics of sliding and slider surfaces on friction coefficient: in vivo human skin friction comparison. Skin Res Technol 2004; 10(4):215-221.

32. Comaish S, Bottoms E. The skin and friction: deviations from Amonton's laws, and the effects of hydration and lubrication. Br J Dermatol 1971; 84(1):37-43. 
33. Highley KR, et al. Frictional properties of skin. J Invest Dermatol 1977; 69(3):303-305.

34. Comaish JS, Harborow PR, Hofman DA. A hand-held friction meter. Br J Dermatol 1973; 89(1):33-35.

35. Sivamani RK, et al. Coefficient of friction: tribological studies in man - an overview. Skin Res Technol 2003; 9(3):227-234.

36. Sivamani RK, et al. Friction coefficient of skin in real-time. Skin Res Technol 2003; 9(3):235-239.

37. Sivamani RK, et al. Tribological testing of skin products: gender, age, and ethnicity on the volar forearm. Skin Res Technol 2003; 9(4):299-305.

38. Kim JJ, et al. Instrumental methods for measuring the surface frictional-properties of softener treated fabrics. Textile Chemist and Colorist 1993; 25(8):15-20.

39. Egawa M, et al. The evaluation of skin friction using a frictional feel analyzer. Skin Res Technol 2002; 8(1):41-51.

40. Tanaka M, et al. The "Haptic Finger"- a new device for monitoring skin condition. Skin Research and Technology 2003; 9(2):131-136.

41. Wolfram LJ. Friction of skin. Journal of the Society of Cosmetic Chemists 1983; 34(8): $465-476$.

42. Koudine AA, et al. Frictional properties of skin: proposal of a new approach. International Journal of Cosmetic Sciences 2000; 22:11-20.

43. Nishimatsu T, et al. Measurement of active tactual motion in judging hand of materials of fabrics. Sen-I Gakkaishi 1998; 54(9):452-458.

44. Gee MG, et al. A new friction measurement system for the frictional component of touch. Wear 2005; 259:1437-1442.

45. Hatch KL, Maibach HI. Textile fiber dermatitis. Contact Dermatitis 1985; 12(1):1-11.

46. Zimmerer RE, Lawson KD, Calvert CJ. The effects of wearing diapers on skin. Pediatr Dermatol 1986; 3(2):95-101.

47. Shafik A, Ibrahim IH, Elsayed EM. Effect of different types of textile fabric on spermatogenesis. 1. Electrostatic potentials generated on surface of human scrotum by wearing different types of fabric. Andrologia 1992; 24(3):145-147.

48. Shafik A. Polyester but not cotton or wool textiles inhibit hair-growth. Dermatology 1993; 187(4):239-242.

49. Farage MA, et al. Development of a new test for mechanical irritation: behind the knee as a test site. Skin Research and Technology 2001; 7(3):193-203.

50. Knapik JJ, et al. Friction blisters. Pathophysiology, prevention and treatment. Sports Med 1995; 20(3):136-147.

51. Sulzberger MB, et al. Studies on blisters produced by friction. I. Results of linear rubbing and twisting technics. J Invest Dermatol 1996; 47(5):456-465 contd.

52. Cortese TA, Jr., et al. Treatment of friction blisters. An experimental study. Arch Dermatol 1968; 97(6):717-721.

53. Cortese TA, Jr., Sams WM, Jr., Sulzberger MB. Studies on blisters produced by friction. II. The blister fluid. J Invest Dermatol 1968; 50(1):47-53.

54. Sulzberger MB, Cortese TA. Observations on the blister base. Br J Clin Pract 1968; 22(6):249-250.

55. Akers WA, Sulzberger MB. The friction blister. Mil Med 1972; 137(1):1-7.

56. Jagoda A, Madden H, Hinson C. A friction blister prevention study in a population of marines. Mil Med 1981; 146(1):42-44.

57. Herring KM, Richie DH, Jr. Friction blisters and sock fiber composition. A double-blind study. J Am Podiatr Med Assoc 1990; 80(2):63-71.

58. Patterson HS, Woolley TW, Lednar WM. Foot blister risk factors in an ROTC summer camp population. Mil Med 1994; 159(2):130-135. 
59. Knapik JJ, et al. Influence of boot-sock systems on frequency and severity of foot blisters. Mil Med 1996; 161(10):594-598.

60. Brueck CM. The role of topical lubrication in the prevention of skin friction in physically challenged athletes. Journal of Sports Chiropractic \& Rehabilitation 2000; 14(2):37-41.

61. Spence WR, Shields MN. Prevention of blisters, callosities and ulcers by absorption of shear forces. J Am Podiatry Assoc 1968; 58(10):428-434.

62. Reynolds K, et al. Effects of an antiperspirant with emollients on foot-sweat accumulation and blister formation while walking in the heat. J Am Acad Dermatol 1995; 33(4):626-630.

63. Knapik JJ, Reynolds K, Barson J. Influence of an antiperspirant on foot blister incidence during cross-country hiking. J Am Acad Dermatol 1998; 39(2 Pt 1):202-206.

64. EPUAP. European pressure ulcer advisory panel guidelines on treatment of pressure ulcers. EPUAP Review 1999; 1:31-33.

65. Bergstrom NI. Strategies for preventing pressure ulcers. Clin Geriatr Med 1997; 13(3):437-454.

66. Beckrich K, Aronovitch SA. Hospital-acquired pressure ulcers: a comparison of costs in medical vs. surgical patients. Nurs Econ 1999; 17(5):263-271.

67. Moore JD, Jr. Bedsores: $\$ 1$ billion burden. N.Y. peer review organization tries education to stop a preventable problem. Mod Healthc 1998; 28(29):43.

68. Keller BP, et al. Pressure ulcers in intensive care patients: a review of risks and prevention. Intensive Care Med 2002; 28(10):1379-1388.

69. Dinsdale SM. Decubitus ulcers: role of pressure and friction in causation. Arch Phys Med Rehabil 1974; 55(4):147-152.

70. Davis BL. Foot ulceration - hypotheses concerning shear and vertical forces acting on adjacent regions of skin. Medical Hypotheses 1993; 40(1):44-47.

71. Maklebust J, Sieggreen M. Pressure ulcers, guidelines for prevention and management, 3rd ed. Pennsylvania: Springhouse, 2001.

72. Morison MJ. ed. The prevention and treatment of pressure ulcers. London: Harcourt Publishers Limited, 2001.

73. Bouza C, et al. Efficacy of advanced dressings in the treatment of pressure ulcers: a systematic review. J Wound Care 2005; 14(5):193-199.

74. Factora R. Year in review: National pressure ulcer long-term care study (NPULS). J Am Med Dir Assoc 2004; 5(5):356-357.

75. Cockett A. A research review to identify the factors contributing to the development of pressure ulcers in paediatric patients. J Tissue Viability 2002; 12(1):16-17, 20-23.

76. Jastremski CA. Pressure relief bedding to prevent pressure ulcer development in critical care. J Crit Care 2002; 17(2):122-125.

77. Theaker C, Kuper M, Soni N. Pressure ulcer prevention in ntensive care - a randomised control trial of two pressure-relieving devices. Anaesthesia 2005; 60(4):395-399.

78. Beghe C. Review: Foam-based, constant low-pressure mattresses are better than standard hospital mattresses for reducing pressure ulcers. ACP J Club 2005; 142(1):8.

79. Veves A, et al. Studies of experimental hosiery in diabetic neuropathic patients with high foot pressures. Diabet Med 1990; 7(4):324-326.

80. Murray HJ, et al. Role of experimental socks in the care of the high-risk diabetic foot. A multicenter patient evaluation study. american group for the study of experimental hosiery in the diabetic foot. Diabetes Care 1993; 16(8):1190-1192.

81. Snycerski M, Frontczak-Wasiak I. A functional woven fabric with controlled friction coefficients preventing bedsores. AUTEX Research Journal 2004; 4(3):137-142. 

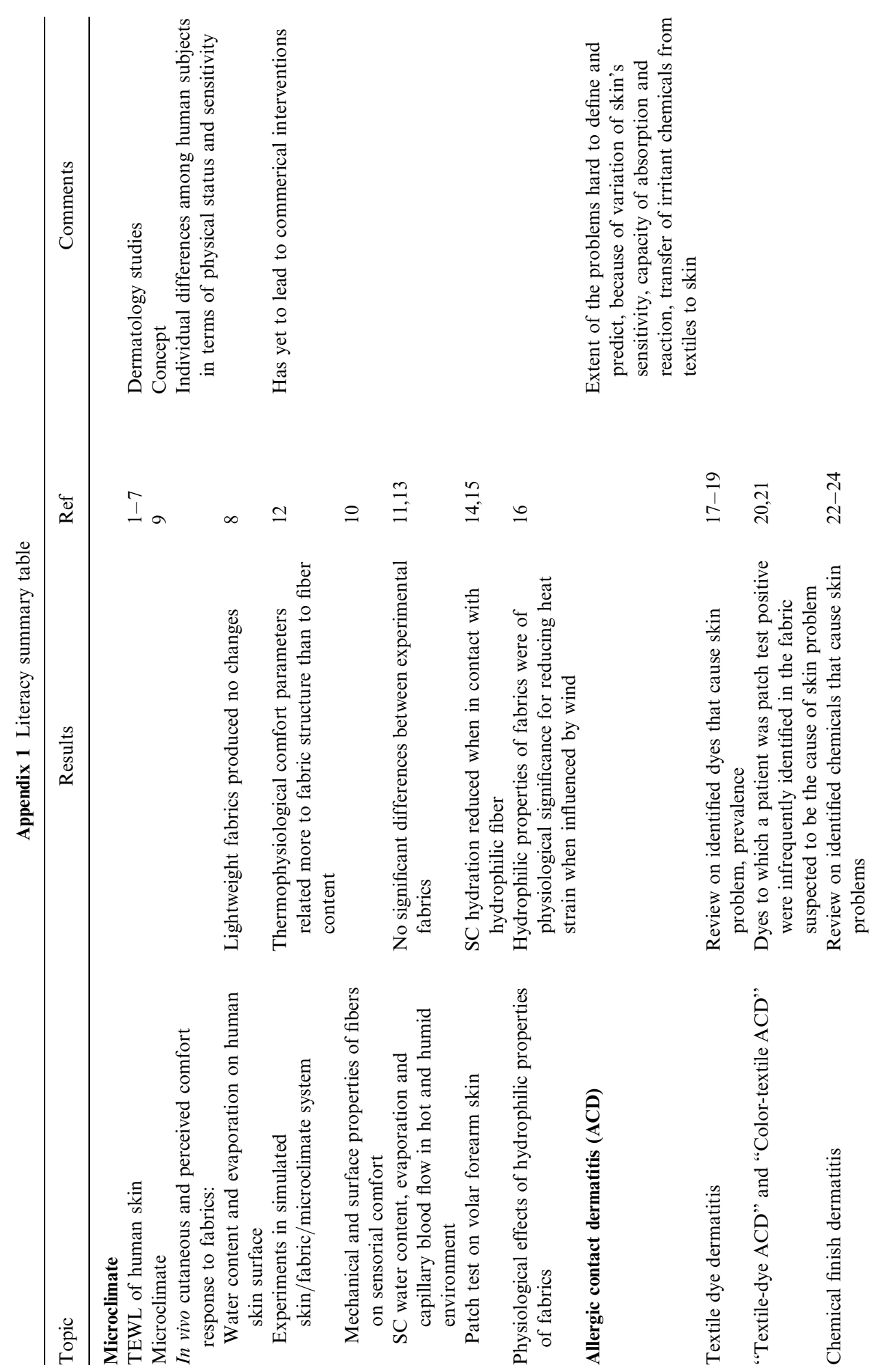


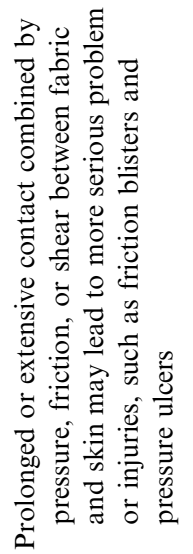

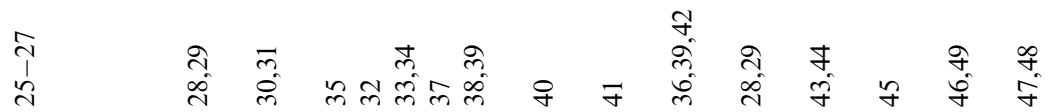
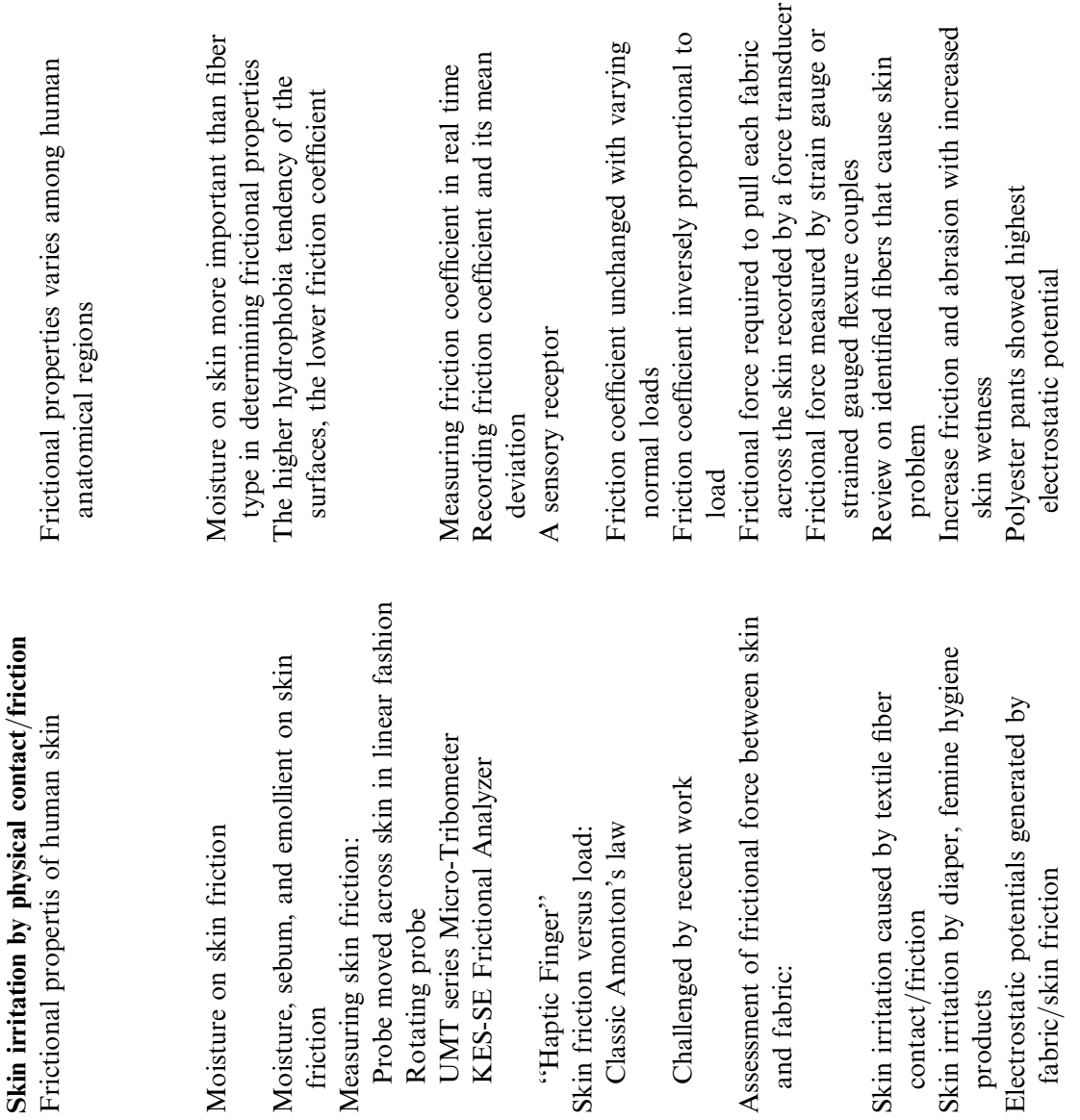

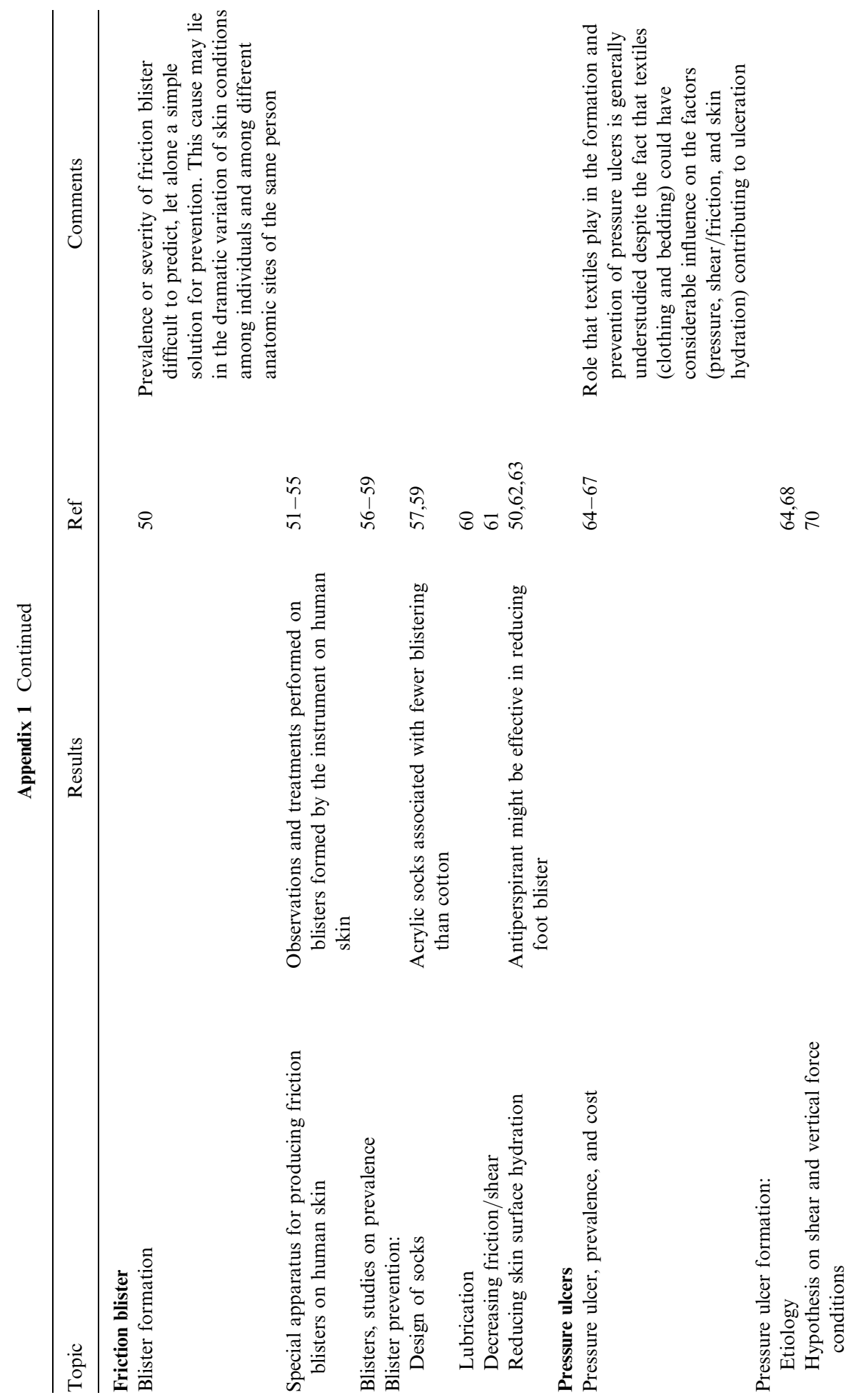


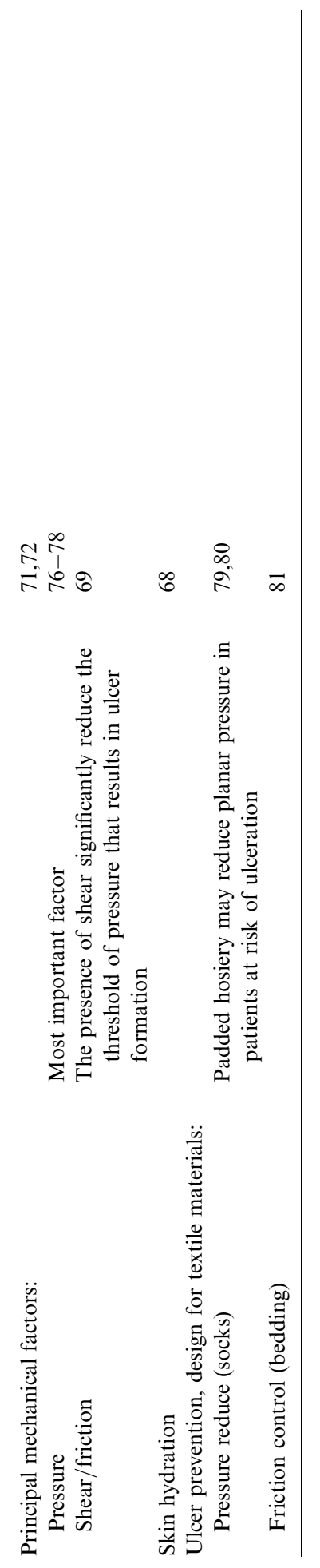

